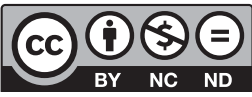

Estudos Teológicos foi licenciado com uma Licença Creative Commons Atribuição - NãoComercial - SemDerivados 3.0 Não Adaptada

http://dx.doi.org/10.22351/et.v60i2.4004

\title{
"SE É PERMITIDO FUGIR DIANTE DA AMEAÇA DE MORTE" LUTERO E A EPIDEMIA DA PESTE EM WITTENBERG ${ }^{1}$
}

\author{
"If one can flee in the face of death" \\ Luther and the epidemic of the plague in Wittenberg
}

\begin{abstract}
Wilhelm Wachholz ${ }^{2}$
Resumo: A morte é companheira da vida. Ela é caroneira da vida. A consciência da existência humana encontra-se no tempo e perante a morte. O reformador Martim Lutero tinha consciência da morte, que lhe foi companheira constante na vida. Este artigo tem por objetivo analisar manifestações de Lutero em meio aos surtos da peste, em particular, em Wittenberg. Após contextualização do ressurgimento e da expansão da peste a partir do século XIV, analisaremos prédicas, cartas e o principal escrito de Lutero sobre o tema, Se é permitido fugir diante da ameaça de morte (1527). Teologia e prática pastoral de Lutero ficam evidenciadas ao se pesquisar o tema da peste em seus escritos. A saúde frágil de Lutero, a experiência da morte de pessoas próximas, por peste ou outras doenças, aguçaram a sensibilidade do reformador sobre o tema da morte, mas, especialmente, do cuidado aos enfermos: sua própria casa tornou-se, em vários momentos, um hospital.
\end{abstract}

Palavras-chave: Lutero. Peste. Morte. Vida. Wittenberg.

Abstract: Death is life's companion. It is life's passenger. The awareness of human existence is found in time and facing death. The reformer Martin Luther was aware of death, which was a constant companion in his life. This article aims to analyze Luther's manifestations in the midst of the plague outbreaks, in particular, in Wittenberg. After contextualizing the resurgence and expansion of the plague from the 14th century onwards, we will analyze sermons, letters and Luther's main writing on the topic, "If one can flee in the face of death" (1527). Luther's theology and pastoral practice are evident when researching the plague theme in his writings. Luther's fragile health, the experience of the death of people close to him, from plague or other illnesses, heightened the reformer's sensitivity on the subject of death, but especially the care for the sick: his own home became, at various times, a hospital.

Keywords: Luther. Plague. Death. Life. Wittenberg.

1 O artigo foi recebido em 20 de maio de 2020 e aprovado em 11 de setembro de 2020 com base nas avaliações dos pareceristas ad hoc.

2 Doutor. Faculdades EST. E-mail: wachholz@est.edu.br 


\section{Introdução}

Após cerca de 600 anos de ausência da peste na Europa - desde o século VIII -, a epidemia $^{3}$ voltou à Europa em 1346, estendendo-se, com picos de surtos, até o século XVIII. A epidemia do século XIV iniciou na região do baixo Volga. De lá se alastrou para a região da Crimeia e, pelo mar Negro, para Trebizonda e Constantinopla, e de Constantinopla pelo Mediterrâneo para Alexandria, Veneza e Gênova. No verão de 1348 já havia se espalhado para a maioria das cidades da Itália, o sul da França e a região mediterrânea da Espanha. Até o final do ano de 1348 atingiu diferentes regiões da Europa continental, além da Irlanda, sudeste da Inglaterra e vale do Sena. ${ }^{4}$

A peste era, na sua origem, uma doença que atingia ratos. Especialmente após os ratos morrerem, as pulgas, neles alojados e transmissores do bacilo, precisavam buscar outros hospedeiros, encontrando-os nos seres humanos. Possivelmente, o surto inicial se deu a partir de pulgas hospedadas em peles de marmotas comercializadas na região sul da Rússia. A epidemia se alastrou fortemente após atingir a população de ratos no litoral do Mediterrâneo, especialmente nas regiões portuárias. A expansão da peste para a Europa ocorreu pelas embarcações mercantes italianas. Ao transportarem ratos, os navios também se tornaram veículos de propagação da peste. Uma vez contaminadas, as pessoas transmitiam umas às outras a doença por meio de espirros e tossidelas. ${ }^{5}$

Além da variante septicêmica, quando o bacilo se alojava na corrente sanguínea, a peste apresentava pelo menos duas outras variantes: pneumônica, que desencadeou o surto na Europa do ano de 1348, e a bubônica, uma variante mais tardia. ${ }^{6}$ Na segunda variante, a denominação tem origem na palavra $b u b a$, que designa a virilha, cujos gânglios linfáticos geralmente eram os primeiros a inchar, uma vez que as pulgas, na maioria das vezes, atacavam e mordiam as pernas. A partir do ataque das pulgas, apareciam manchas ou pústulas negras (por essa razão a doença foi denominada de "Peste Negra" ou também "Morte Negra) devido ao sangramento subcutâneo. Seguiam-se, então, as tossidelas, que, no estágio final da vida, eram de sangue puro. A situação dos doentes foi descrita assim:

Toda substância que exsudava de seus corpos exalava um mau cheiro insuportável; o suor, os excrementos, os escarros e o bafo eram tão fétidos que chegavam a ser prostradores; a urina ficava turva, espessa, negra ou então vermelha ${ }^{7}$.

\footnotetext{
Utilizaremos o conceito epidemia (e não pandemia ou endemia) pelo fato de Martim Lutero utilizá-lo, junto com conceitos como "peste" e "pestilência".

4 BRAUDEL, Fernand. Sozialgeschichte des 15.-18. Jahrhunderts. München: Kindler, 1985. p. 86; McEVEDY, Colin. Atlas de história medieval. São Paulo: Companhia das Letras, 2007. p. 94.

5 LINDBERG, Carter. As Reformas na Europa. São Leopoldo: Sinodal, 2001. p. 41; BRAUDEL, 1985, p. 80-81; McEVEDY, 2007, p. 94.

6 BRAUDEL, 1985, p. 80.

7 McKAY, John; HILL, Bennett; BUCKLER, John (ed.). A History of World Societies. 2. ed. Boston: Houghton Mifflin, 1988. v. 1, p. 430, apud LINDBERG, 2001, p. 42.
} 
As estimativas de mortandade entre a população humana são bastante incertas. Registros indicam de 50\% a 75\% de mortalidade. Na Inglaterra, por exemplo, pelo menos $1 / 3$ do clero faleceu pela epidemia. Ao final do quarto ano da epidemia, em 1349, estima-se que cerca de 15 milhões de pessoas haviam perdido a vida na Europa, Norte da África e no Levante. ${ }^{8}$

A partir de 1350, a peste espalhou-se pela Europa, especialmente na Alemanha e Suécia. No ano seguinte, alcançou a Polônia e, em 1352, a Rússia. Moscou foi atingida em 1353. Por fim, numa aldeia do Volga, distante somente algumas centenas de quilômetros do foco inicial da epidemia sete anos antes, ocorreu um último surto. $\mathrm{O}$ bacilo da peste, contudo, havia conseguido refúgio em regiões rurais da Alemanha, irrompendo novamente em 1357. Esse surto se estendeu por cerca de oito anos, causando grande mortalidade, sobretudo, nas regiões que haviam ficado intactas no primeiro surto. Até o final daquele século, a peste impactaria em intervalos aproximados de dez anos, reduzindo a população europeia a cerca de 60 milhões de pessoas. ${ }^{9}$

A peste impactou profundamente na vida social e individual da humanidade medieval. Não se conhecia sua origem. Em poucos dias, uma pessoa sadia atingida pela peste, especialmente a variante septicêmica, poderia morrer. Por essa razão o temor da morte iminente e horrível povoava o imaginário do ser humano medieval. Pais abandonavam filhos e vice-versa - como veremos abaixo, ainda à época de Lutero, pessoas infectadas pela peste eram abandonadas à própria sorte. A peste foi compreendida, em grande medida, como punição de Deus pelos pecados do ser humano. Por isso a prática do autoflagelo se tornou comum. Tragicamente, ao realizarem procissões visando à expiação dos pecados, as pessoas aceleravam a transmissão da peste. ${ }^{10}$ Da obra de Bocácio, Decameron (1353), lemos:

No ano de Nosso Senhor de 1348, ocorreu em Florença, a mais bela cidade de toda a Itália, uma peste terrível, que, seja devido à influência dos planetas, ou seja como castigo de Deus aos nossos pecados, surgira alguns anos antes no Levante (Oriente Médio) e, depois, de passar de um lugar para outro, provocando grandes danos em toda a parte, atingiu o Ocidente. Aqui, a despeito de todos os meios que a arte e a previsão humana poderiam sugerir, como manter a cidade limpa, exclusão de todas as pessoas suspeitas de moléstias e publicação de copiosas instruções para a preservação da saúde, e não obstante as múltiplas e humildes súplicas oferecidas a Deus em procissões e de outras formas, começou a se evidenciar na primavera do mencionado ano, de maneira triste e surpreendente [...] Para a cura da doença, nem o conhecimento médico nem o poder das drogas tinham qualquer efeito [...] Qualquer que fosse a razão, poucos escaparam,

\footnotetext{
McEVEDY, 2007, p. 94; LINDBERG, 2001, p. 41-42.

9 McEVEDY, 2007, p. 94. Entre os séculos XIV e XVIII, os maiores surtos na Europa ocorreram em torno dos seguintes anos: 1348-1350, 1360/1361, 1369-1374, 1380/1381, 1412, 1425/1426, 1430/1431, 1439, 1456-1457, 1464-1466, 1481-1485, 1500-1503, 1518-1531, 1544-1548, 1563-1566, 1573-1588, 15961599, 1602-1611, 1623-1640, 1644-1654 e 1664-1667. DER GROSSE PLOETZ. Die Daten Enzyklopädie der Weltgeschichte. Daten, Fakten Zusammenhängen. Freiburg im Breisgau: Wissenschaftliche Buchgesellschaft, 1998. p. 408. Sobre surtos em diferentes regiões europeias entre os séculos XV e XVIII, veja BRAUDEL, 1985, p. 82-86.

${ }^{10}$ LINDBERG, 2001, p. 43.
} 
e quase todos morriam no terceiro dia após o aparecimento dos sintomas [...] O que deu a essa peste maior virulência foi o fato de passar do doente para o são, aumentando diariamente, como o fogo em contato com grande massa de combustíveis [...] Essa, segundo me parece, a qualidade da peste, de passar não apenas de homem para homem, mas o que era ainda mais estranho, qualquer coisas pertencente ao doente, se tocada por outra criatura, transmitia com certeza a doença, e a matava num curto espaço de tempo. Pude observar um exemplo disso: os trapos de um pobre que acabava de morrer foram lançados à rua; dois cães surgiram e, depois de brigarem por eles e sacudi-los na boca, em menos de uma hora caíram mortos ${ }^{11}$.

\section{O tema da peste nas obras de Lutero}

Os termos "peste" ou "pestilência" são empregados por Lutero não somente em relação à peste como doença (septicêmica, pneumônica ou bubônica), mas também em sentidos diversos. Em carta datada de maio de 1518 ao papa Leão X, por exemplo, ele faz referência a si próprio como "peste". Nessa carta, acompanhada de cópias de suas obras ao papa ${ }^{12}$, Lutero se defende de seus adversários e, em caráter retórico, observa que o príncipe-eleitor da Saxônia, Frederico, que seria um defensor da verdade católica e apostólica, não teria trazido à universidade um "peste" [referindo-se a si próprio] leviano. ${ }^{13}$

O emprego mais comum do termo "peste" ou sua variante "pestilência" (quando não se refere propriamente à epidemia da peste septicêmica, bubônica ou pneumônica) é teológico, a partir da distinção que o reformador faz de lei e evangelho. Segundo Bayer, para Lutero, "diferentemente da lei, na qual Deus fala contra mim, no evangelho ele fala em meu favor" ${ }^{14}$. Concretamente, a respeito da peste, segundo Lutero, a lei denuncia o pecado humano, mas, ao mesmo tempo, Deus não somente "fala contra" o ser humano pecador, senão que também "a seu favor" (evangelho), consolando-o com a promessa da

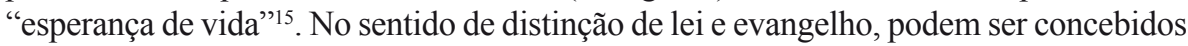
os exemplos extraídos de textos de Lutero a seguir.

Em Do Cativeiro Babilonico da Igreja (1520), no contexto da discussão sobre a função do diaconato - "distribuir as riquezas da Igreja entre os pobres, para que os sacerdotes sejam liberados do ônus das coisas temporais e possam dedicar-se com maior liberdade à obra e à Palavra" -, Lutero denuncia que "quem não sabe ou não prega o Evangelho não só não é sacerdote ou bispo, mas é uma peste na Igreja $^{16}$, al-

11 Apud ARRUDA, José Jobson de. História Antiga e Medieval. 3. ed. São Paulo: Ática, 1979. p. 429.

12 Há que se considerar que Lutero havia publicado, em fins de outubro ou início de novembro do ano anterior, suas 95 teses, que repercutiram fortemente em Roma.

${ }^{13}$ LUTHER, Martin. Brief an Papst Leo X. (Mai 1518). In: ALAND, Kurt (Hrsg.). Gesammelte Werke. Bd. 2, p. 91.

14 BAYER, Oswald. A teologia de Martim Lutero. São Leopoldo: Sinodal, 2007. p. 44.

15 Sobre o conceito "esperança de vida", veja LUTERO, Martinho. Preleção sobre Gênesis. In: Obras Selecionadas. Interpretação do Antigo Testamento. São Leopoldo: Sinodal, Porto Alegre: Concórdia; Canoas: Ulbra, 2014. p. 105, 116, 121, 213, 237, 251.

16 A seguir, as expressões serão sublinhadas para fins de destaque de como aparecem nos textos citados de Lutero. 
guém que, sob o falso título de sacerdote e bispo, como sob pele de ovelha, oprime o Evangelho e age como lobo na Igreja"17.

Em vários textos, peste aparece ligado à concepção de "lei”. Em sua Preleção Acerca da Carta aos Romanos (1515-1516), o reformador emprega o termo para designar a "peste do orgulho"18. Segundo Lutero, o ser humano dificilmente faz autoexame para reconhecer a "peste da fraqueza de sua vontade", por isso também raramente reconhece a graça de Deus. ${ }^{19}$ Semelhantemente, na explicação do segundo mandamento, no Catecismo Maior (1529), segundo o reformador, por causa do pecado, "recebemos em paga aquilo que procuramos e merecemos: peste, guerra ${ }^{20}$, carestia, incêndios, inundações, mulheres, filhos e empregados ruins, e toda a sorte de males"21. Em Uma Prédica para que se Mandem os Filhos à Escola (1530), Lutero denuncia que o ser humano contribui para a ruína do reino de Deus e a salvação das almas e alerta: "Não seria motivo para Deus irar-se? Não deveria sobrevir um tempo de carestia? Não deveriam atingir-nos pestilências, a peste inglesa, a epidemia francesa e outras pragas?" 22 . Em 1532, numa prédica sobre Mateus 7.15-23, o termo peste também é utilizado como castigo, portanto no sentido de lei. Segundo ele, onde não há fé em Deus e onde não há verdadeira obediência e respeito entre as pessoas, as consequências são peste, carestia, fome, guerra e toda sorte de infelicidade, como pagamento pelo desprezo à palavra de Deus. ${ }^{23}$

Lutero, contudo, não somente concebe os castigos de Deus negativamente. Nas Conversações à Mesa [Tischreden], ele afirma que, quando Deus fala, castiga, se zanga ou branda contra o ser humano, quando deixa inimigos dominarem sobre nós, quando nos envia peste, fome, espada ou outras pragas, é sinal de que ele quer nosso bem, portanto, anuncia o evangelho. Se tudo isso não nos acontece mais, seria sinal, segundo Lutero, que Deus se afastou de nós. ${ }^{24}$

${ }^{17}$ LUTERO, Martinho. Do cativeiro babilônico da Igreja; um prelúdio de Martinho Lutero. In. Obras Selecionadas. O programa da Reforma Escritos de 1520. São Leopoldo: Sinodal; Porto Alegre: Concórdia, 1989. v. 2, p. 417.

18 LUTHER, Martin. Vorlesung über den Römerbrief (1515/1516). In: ALAND, Kurt (Hrsg.). Gesammelte Werke. Bd. 1, p. 136.

${ }^{19}$ LUTHER, Martin. Vorlesung über den Römerbrief (1515/1516). In: ALAND, Kurt (Hrsg.). Gesammelte Werke. Bd. 1, p. 145.

${ }^{20}$ Lutero considera a guerra o maior de todos os castigos, pois destrói a religião e os regimentos doméstico e secular. Pestilência e fome não podem ser comparadas com a guerra. Aliás, para ele, a pestilência é o castigo mais brando, razão pela qual o rei Davi teria escolhido a pestilência entre três possíveis castigos [cf. 2Sm 24.1-17]. LUTHER, Martin. Über den Krieg. Obrigkeit und Staat. In: ALAND, Kurt (Hrsg.). Gesammelte Werke. Bd. 9, p. 205.

${ }^{21}$ LUTERO, Martinho. Catecismo Maior do Dr. Martinho Lutero. In: Livro de Concórdia; as confissões da Igreja Evangélica Luterana. São Leopoldo: Sinodal; Porto Alegre: Concórdia, 1997. p. 403.

${ }^{22}$ LUTERO, Martinho. Uma Prédica para que se Mandem os Filhos à Escola. In: Obras Selecionadas. Fundamentos - Oração - Sexualidade - Educação - Economia. São Leopoldo: Sinodal; Porto Alegre: Concórdia, 1995. v. 5, p. 360.

${ }^{23}$ LUTHER, Luther. Achter Sonntag nach Trinitatis. Matth. 7,15-23. In: ALAND, Kurt (Hrsg.). Gesammelte Werke. Bd. 8, p. 315.

${ }^{24}$ LUTHER, Martin. Zeichen, wenn Gott gnädig oder ungnädig sei. Der neue Glaube. In: ALAND, Kurt (Hrsg.). Gesammelte Werke. Bd. 9, p. 87. 
Ainda assim, o mal (a peste), segundo Lutero, não vem de Deus, mas por meio do diabo. Também em suas Conversações à Mesa [Tischreden], Lutero afirma que Deus permite que o diabo proceda maldades quando desprezamos Deus. Mas tudo o que tem a ver com a morte é obra do diabo, enquanto o que tem a ver com vida é graça de Deus. O diabo é o carrasco de Deus. Na peste, o diabo assopra para dentro das casas e, o que ele atinge com seu sopro, ele leva junto. ${ }^{25}$ Desta forma, o diabo é exatamente o contrário de Deus. Enquanto Deus sopra seu hálito que cria (Gn 2.7), o ser humano como "alma viva" ${ }^{26}$ o diabo é assassino, ao assoprar o ar da peste que mata.

Em 1531, em uma prédica sobre Mateus 8.23-27, Lutero afirma que o livre-arbítrio não é nada, enquanto a fé é tudo. Segundo ele, o texto bíblico relata o perigo em que os discípulos se encontram e que, nessa situação, a fé lhes é consolo e alegria, pois Deus é a força. Então Lutero cita a peste ao questionar: caso você seja destemido, tente [salvar-se a si próprio], com seu livre-arbítrio quando peste, guerra e fome sobrevierem. Segundo Lutero, em meio à peste, por causa do medo, a pessoa fica paralisada. Não faltaria vontade, mas essa vontade não consegue operar nada. ${ }^{27}$ Por essa razão não é o livre-arbítrio que tem a força da salvação, mas a fé.

Em uma prédica sobre Lucas 14.16-24, de 1532, Lutero caracteriza a fé em Jesus Cristo. Pela fé no evangelho, a pessoa degusta Cristo e sua alma é apascentada e fortalecida, e experimenta perdão dos pecados, vida eterna e salvação. Assim, em meio a morte, peste, fome, perigo, medo e temor e todos os clamores, o evangelho é alimento para toda a fome e sede. ${ }^{28}$ Em uma prédica sobre Mateus 9.18-26, datada de 1529, Lutero apresenta Jesus Cristo como auxiliador e salvador em meio à grande necessidade, a saber, a morte. Ele ressalta que todas as pessoas precisarão morrer, desde Adão, até a última pessoa. Segundo Lutero, algumas morrem afogadas, outras condenadas no fogo; umas, pela peste; outras, pela epidemia; nada é mais certo do que a própria morte. $\mathrm{O}$ texto de Mateus, segundo Lutero, ensina Cristo; não nos ensina como se pode ficar rico, mas como ser redimido da morte. Lutero, então, se vale do exemplo de uma pessoa contagiada pela peste, que não aceita remédio receitado por um médico, respondendo que prefere morrer. Tal enfermo seria considerado estúpido. Assim são, segundo Lutero, as pessoas que não creem: até mesmo quando a morte se apresenta como ameaça, não desviam dela nem buscam por um médico. Cristo é auxiliador, mesmo quando todos os amigos abandonam a pessoa ou quando todo mundo não puder ajudá-la. ${ }^{29}$

${ }^{25}$ LUTHER, Martin. Der Teufel; die Ursache von Not, Traurigkeit und Krankheit. Der Christ in der Welt. In: ALAND, Kurt (Hrsg.). Gesammelte Werke. Bd. 9, p. 285. Cabe observar que, para Lutero, a peste é transmitida pelo ar. Então, assim como Deus soprou nas narinas do primeiro ser humano, dando-lhe vida, o diabo sopra o ar da peste, que mata o ser humano.

${ }^{26}$ LUTERO, 2014, p. 120-121.

${ }^{27}$ LUTHER, Martin. Vierter Sonntag nach Epiphanias. Matth. 8,23-27. In: ALAND, Kurt (Hrsg.). Gesammelte Werke. Bd. 8, p. 98.

${ }^{28}$ LUTHER, Martin. Zweiter Sonntag nach Trinitatis. Luk. 14,16-24. In: ALAND, Kurt (Hrsg.). Gesammelte Werke. Bd. 8, p. 274-275.

${ }^{29}$ LUTHER, Martin. Vierundzwanzigster Sonntag nach Trinitatis. Matth. 9,18-26. In: ALAND, Kurt (Hrsg.). Gesammelte Werke. Bd. 8, p. 415-417. 
Finalmente, destacamos uma prédica de Lutero sobre João 15.26 - 16.4, datada de 1532, na qual ele aborda dois tipos de consolo: aquele oferecido pelo mundo e aquele do Espírito Santo. O consolo mundano é falso e mentiroso, pois consiste de bens, honra, poder, amizade e favores de grandes príncipes e senhores. Mas todo poder, honra, bens e virtudes serão usados contra "vocês", segundo Lutero. Esse tipo de consolo não resiste até que uma febre, peste ou outra doença sobrevenham. Diferente é o consolo do Espírito Santo, que consola a pessoa em seu coração e diante de outras pessoas, quando estiver assustada, falida, abandonada e em miséria e pobreza. Por isso o Espírito Santo é chamado de consolador e não de enganador. ${ }^{30}$

\section{$O$ ano de 1505: peste, mortes e o mosteiro}

A morte era companheira na vida do ser humano medieval. Ela também se apresentou a Lutero como companheira. A decisão de Lutero de interromper seus estudos de Direito, em maio de $1505^{31}$, tem a ver com uma consciência impactada por experiências dramáticas. À época do jovem Lutero, relatava-se que, moribundos, dois juristas teriam proferidos como últimas palavras as seguintes: “Ó, tivesse sido eu monge". E, de fato, três juristas de Erfurt haviam falecido, sendo pelo menos um, talvez até dois, bem pouco antes da entrada de Lutero no mosteiro agostiniano de Erfurt. O primeiro, João Klockereim, que era vice-chanceler da Universidade de Erfurt, morrera já em junho de 1501. No dia 03 de abril de 1505, faleceria Henrique Collen, decano da Faculdade de Direito da Universidade de Erfurt e, ainda em 1505, Siegfredo Ziegler. Os dois últimos perderam a vida provavelmente em consequência da peste. Lutero possivelmente assistiu às missas de corpo presente dos dois últimos. Os falecimentos desses juristas podem ter contribuído para a insegurança de Lutero na continuidade dos estudos de Direito. Possivelmente teve consciência de que servir a Deus seria algo diferente do que desempenhar a atividade jurídica. Não se pode afirmar se Lutero já tinha conhecimento, nesta ocasião, da arrogância dos juristas, tratando teólogos como burros. Em todo caso, mais tarde, Lutero afirmaria sobre o jurista de Wittenberg, Henning Göde, que ele não entendia nada de religião. ${ }^{32}$

A experiência da proximidade da morte se apresentou para Lutero de forma mais concreta com o surto da peste no ano de 1505. Além do falecimento de ambos os juristas, mais dois estudantes das relações de Lutero, sendo um Hieronymus Buntz, perderam a vida em decorrência da epidemia. Também essas duas mortes foram vivenciadas por Lutero. $\mathrm{O}$ medo de uma morte rápida se tornava muito concreta e existencial para cada pessoa. Certamente a consciência de Lutero de ter de responder ao

${ }^{30}$ LUTHER, Martin. Sonntag Exaudi. Joh. 15,26-16, 4. In: ALAND, Kurt (Hrsg.). Gesammelte Werke. Bd. 8, p. 237-238.

${ }^{31}$ Sobre os estudos de Lutero, veja LIENHARD, Marc. Martim Lutero; tempo, vida e mensagem. São Leopoldo: Sinodal, 1998. p. 32-34.

32 BRECHT, Martin. Martin Luther; Sein Weg zur Reformation 1483-1521. Stuttgart: Calwer Verlag, 1983. v. 1, p. 54. 
julgamento de Deus não eclodiu somente quando ele estava no mosteiro, mas já teve importância nos passos que o levariam à vida monástica. ${ }^{33}$

\section{Os anos de 1527 a 1529: Se é permitido fugir diante da ameaça de morte}

Um novo surto da peste é registrado no outono de 1516, quando Lutero já se encontrava em Wittenberg. O próprio Lutero, em carta a João Lang, de 26 de outubro de 1516, relatou que, quase todos os dias, duas ou três pessoas eram sepultadas em consequência da peste. Embora tenha manifestado medo da peste, não saiu de Wittenberg, enquanto, no geral, os monges foram aconselhados a se espalhar em outros lugarejos em caso de necessidade..$^{34}$ Esse surto, aparentemente, não se espalhou com tanta força em Wittenberg, pois não há mais registros de Lutero sobre o assunto nessa época.

No final da década de 1520 ocorreu um novo surto da peste em Wittenberg. Nesse contexto, então, merecem destaque na biografia de Martim Lutero a deterioração de sua saúde, seu casamento com Catarina von Bora e o falecimento da filha Elisabeta. Martim Lutero e Catarina von Bora se casaram em 13 de junho de 1525, quando ele tinha 42 anos e ela, 26 anos de idade. Existem poucos registros sobre o envolvimento de Catarina no cuidado a pessoas contagiadas pela peste e hospedadas na casa do casal, mas Dalferth afirma que "a maior responsabilidade estava sobre os ombros [de Catarina]" ${ }^{35}$. Catarina tinha grande habilidade no cuidado a pessoas doentes, a começar com o próprio marido Martim, que, não raramente, foi seu "paciente". Ela tinha uma farmácia caseira, com medicamentos preparados por ela mesma a partir de ervas, chás, pomadas. Um dos filhos do casal, Paulo, que se tornaria médico, escreveu que sua mãe teria auxiliado muitas pessoas com conselhos e tratamentos, especialmente, mulheres. ${ }^{36}$ Ainda que haja poucos registros do envolvimento de Catarina von Bora no cuidado a pessoas acometidas pela peste, ela teve papel significativo, o que fica evidenciado no fato de pessoas enfermas - não somente pela peste - terem sido hospedadas na residência do casal.

Martim Lutero e Catarina von Bora podem também ter experimentado a peste no falecimento da filha Elisabeta. Há pouco registrado pelo reformador sobre o falecimento dessa filha. Elisabeta havia nascido em 10 de dezembro de 1527 e falecido com menos de um ano de idade, em 03 de agosto de 1528, provavelmente de laringite aguda ou da peste. ${ }^{37}$ Em carta a Nicolaus Hausmann, dois dias após o falecimento da

33 BRECHT, 1983, p. 54.

${ }^{34}$ LUTHER, Martin. An Joh. Lang. 26. Oktober 1516. In: ALAND, Kurt (Hrsg.). Gesammelte Werke. Bd. 10, p. 18; BRECHT, 1983, p. 159.

35 DALFERTH, Heloisa Gralow. Katharina von Bora; uma biografia. São Leopoldo: Sinodal, 2000. p. 77.

36 DALFERTH, 2000, p. 75-79.

37 WACHHOLZ, Wilhelm. História e teologia da Reforma. São Leopoldo: Sinodal, 2010. p. 69; DALFERTH, 2000 , p. 67. 
filha, em 05 de agosto, Lutero expressa seu luto, ressaltando que nunca antes teria acreditado que uma criança fosse "amolecer" tanto o seu coração. ${ }^{38}$

A biografia de Catarina von Bora, já viúva, ficaria mais uma vez marcada pela peste, especialmente no último ano de sua vida, quando foi confrontada novamente com a epidemia. No verão de 1552 ocorreu um novo e forte surto de peste na cidade de Wittenberg. Nessa ocasião, a Universidade de Wittenberg foi transferida para Torgau. Em setembro daquele ano, Catarina foge com seus filhos para Torgau. Durante a viagem, os cavalos se assustaram e Catarina salta da carroça e, na queda, bate fortemente no chão e cai em um fosso de água fria, em consequência do que sofre uma paralisia e forte resfriado. Acamada por mais de dois meses, pouco antes do Natal, em 20 de dezembro de 1552, ela falece e é sepultada na Igreja Matriz de Torgau.

Quanto a Martim Lutero, ele gozou de uma saúde muito boa até por volta do ano de 1524. No final de outubro daquele ano, Filipe Melanchthon relata sobre um mal-estar de Lutero, possivelmente em consequência de estresse por causa do conflito com seu antigo colega professor Andreas Bodenstein von Karlstadt. Nos meses seguintes, o estresse de Lutero seria aumentado, especialmente em decorrência da Guerra dos Camponeses. Além disso, Lutero já se queixava de hemorroidas e, em janeiro de 1525, de uma úlcera na perna. Três anos mais tarde, ele apresenta problemas de circulação sanguínea e falta de ar, evidenciando os primeiros sintomas de uma Angina pectoris. No dia 22 de abril de 1527, Lutero foi obrigado a interromper sua pregação devido à tontura. Em 06 de julho do mesmo ano, ele é acometido de um desmaio, associado a um forte zunido no ouvido esquerdo. Nessa ocasião, Lutero tem o sentimento de que a morte lhe está próxima. Ele se recuperou e interpretou o episódio como "escola de Deus" para sua vida. Embora houvesse quem interpretasse se tratar de sintomas de uma depressão, dificilmente se pode afirmar com certeza se o desencadeamento teve fundo físico, psicológico ou religioso. Ainda nos meses de agosto e setembro, Lutero tinha que lidar com sintomas da doença. ${ }^{39}$

No início de 1529, Lutero teve de interromper suas preleções na Universidade de Wittenberg, pois a tontura e o zunido no ouvido lhe haviam acometido fortemente. Ele próprio não sabia se a causa seria estresse ou tentação diabólica. Nesse contexto, ele pediu que seus amigos intercedessem em oração diante de Deus para o fortalecimento de sua fé. Em abril de 1529, ele foi acometido de uma forte gripe, com muito catarro, ficando sem voz. Somente no início de maio ele conseguiu retomar as atividades docentes na universidade. ${ }^{40}$

No verão de 1529, a "doença do suor inglês" gerou histeria coletiva em Wittenberg, embora não atingisse a cidade. Embora o suor fosse um sintoma da doença - naquele ano, Lutero já lutava há três anos com suor excessivo -, ele se sentia fisicamente

${ }^{38}$ LUTHER, Martin. An Nikolaus Haussmann, 5. August 1528. In: ALAND, Kurt (Hrsg.). Gesammelte Werke. Bd. 10, p. 189.

39 BRECHT, Martin. Martin Luther; Ordnung und Abgrenzung der Reformation 1521-1532. Stuttgart: Calwer Verlag, 1986. v. 2, p. 203-205; JUNGHANS, Helmar. Temas da Teologia de Lutero. São Leopoldo: Sinodal, 2001. p. 87-88.

${ }^{40}$ BRECHT, 1986, p. 208. 
saudável e não infectado pela epidemia, mas enfraquecido na fé. Finalmente, após sua viagem de retorno de Marburgo em outubro daquele ano ${ }^{41}$, ele se encontrava novamente doente, de forma que quase não conseguia escrever. ${ }^{42}$

Especialmente a partir de 1527, encontramos um Lutero acometido de doenças. As interpretações sobre as doenças de Lutero sempre de novo relacionavam seus problemas de circulação sanguínea, depressão e provações na fé. Segundo Brecht, contudo, dever-se-ia ser cuidadoso na definição de uma patologia psíquica específica em Lutero. Lutero procurou, à sua maneira, lidar com sua doença, sobretudo, espiritualmente. $\mathrm{O}$ fato é que ele raramente interrompeu suas atividades em decorrência de suas doenças. ${ }^{43}$

Segundo Junghans, médicos à época não puderam diagnosticar e dar resposta a Lutero a respeito de sua enfermidade. Somente em 1861, um médico francês, Prosper Menière (1799-1862), descreveu que se tratava

[...] de uma enfermidade no ouvido interno em que fluídos normalmente separados acabam se misturando. Isso provoca zunido no ouvido, acessos de fraqueza, tontura, mal-estar, dependendo das circunstâncias até vômito, suor e também desmaio. As pessoas enfermas são assaltadas por medo da morte, mesmo que tais acessos não levem à morte. Após um sono profundo, elas se sentem libertas e salvas. Permanece um zunido menos intenso no ouvido, que em geral fica com a função auditiva dificultada. Somente em 1988, Harald Feldmann, diretor da clínica de otorrinolaringologia da Universidade de Münster/Alemanha, diagnosticou os acessos de dor de Lutero como mal de Menière ${ }^{44}$.

Nesse contexto de doenças, recém-casado com Catarina von Bora e pai, em 1527 irrompeu em Wittenberg a epidemia da peste, que persistiu por vários meses. As atividades da Universidade de Wittenberg foram, em grande medida, transferidas para a cidade de Jena. João Frederico, duque da Saxônia, queria que Lutero também fosse para Jena, a fim de ficar preservado da contaminação. Lutero, no entanto, permaneceu em Wittenberg e continuou suas atividades docentes com número reduzido de discentes. O medo diante da epidemia tomou conta da população, vitimando inclusive pessoas do círculo de relações de Lutero. Exatamente por essa razão, Lutero entendia que deveria permanecer em Wittenberg, juntamente com o pastor João Bugenhagen e os capelães Jorge Rörer e João Mantel. O próprio Lutero exerceu a poimênica junto a pessoas contagiadas. Assim, por exemplo, ele mesmo relataria que a esposa do prefeito Tilo Dene faleceu "quase" em seus braços. A grande mortalidade tornou as pessoas letárgicas, apáticas, indiferentes. Em meados de setembro de 1527, relata-se que, nos sepultamentos, trabalhavam bêbados (coveiros, possivelmente) que tratavam os fami-

${ }^{41}$ Em Marburgo, Lutero participou de um colóquio juntamente com o reformador protestante da Suíça, Ulrico Zwínglio, sobre as divergências entre ambos acerca da Eucaristia. GASSMANN, Günther; HENDRIX, Scott. As confissões luteranas: introdução. São Leopoldo: Sinodal, 2002. p. 108, 199; LINDBERG, 2001, p. 216-217, 228, 234-235.

42 BRECHT, 1986, p. 208.

43 BRECHT, 1986, p. 208-209.

44 JUNGHANS, 2001, p. 88. 
liares enlutados de forma grosseira. O próprio Lutero tematizou o comportamento das pessoas em tempos tão perigosos, conclamando para o amor ao próximo. Ele também repreendeu cônjuges que, por causa da epidemia, abandonavam suas esposas ou seus esposos à própria sorte. ${ }^{45}$

Ainda em agosto, numa carta a Jorge Espalatino, datada do dia 19, Lutero compartilha que a peste teria iniciado em Wittenberg. Segundo Lutero, Satanás estaria provocando medo e fuga das pessoas, como ele nunca tinha visto antes. Satanás estaria se alegrando em tornar os corações fracos, especialmente para acabar com a universidade (única da Reforma!) que ele (Satanás) mais odeia. Ainda assim, segundo Lutero, até aquele dia não mais de 18 pessoas, entre meninos e meninas, haviam falecido. Mas, segundo o reformador, também pessoas já teriam sido curadas por remédios. Lamentavelmente, segundo Lutero, havia pessoas que se negavam a tomar remédios e acabaram falecendo. ${ }^{46}$

Possivelmente ainda no mês de agosto daquele ano, após várias solicitações do pregador e líder da Reforma de Breslau, João Hess, Lutero iniciou a escrever Se é permitido fugir diante da ameaça de morte ["Ob man vor dem Sterben fliehen möge"] ${ }^{47}$. Devido ao frágil estado de saúde, Lutero concluiria o texto somente após algumas semanas. Um surto de peste havia iniciado em Breslau. Inicialmente Lutero não respondeu à solicitação de orientação. Somente quando um surto da peste ocorreu também em Wittenberg, ele escreve para João Hess. Como já ressaltado, Lutero escreveu esse panfleto em situação de saúde fragilizada e em meio a grandes tentações. No mês de julho, a morte lhe parecia próxima. Então a peste atingiu a cidade de Wittenberg, sendo a universidade transferida para Jena. Lutero permaneceu como único professor da universidade, junto com Bugenhagen, que era pastor da cidade. Assim, por ocasião da escrita do panfleto, Lutero já experimentava as consequências do pavor e da fuga da população (mirus hominum pavor et fuga), provocados, segundo ele, pelo diabo. ${ }^{48}$

Lutero inicia o escrito constatando que existiam dois tipos de pessoas e grupos: uns, que entendiam que não se deveria fugir em tempos de epidemia, pois a morte seria punição de Deus para os pecados humanos, por isso se deveria esperar pacientemente em fé firme e forte. Esse grupo, segundo Lutero, concebe a fuga como injustiça e falta de fé em Deus. Outro grupo defende que pessoas deviam fugir, especialmente, aquelas que não teriam responsabilidade com alguma função no serviço público. ${ }^{49}$

A argumentação de Lutero que segue é bastante prudente, não incorrendo num heroísmo ou "martirismo". Ele exalta a iniciativa de pessoas que, por causa da fé e por ser a epidemia destino divino, não fugiam, mas também não torna obrigatória a

45 BRECHT, 1986, p. 205-206, 244.

${ }^{46}$ LUTHER, Martin. an Spalatin, 19. August 1527. In: ALAND, Kurt (Hrsg.). Gesammelte Werke. Bd. 10, p.

47 183. Segundo uma tradução mais livre: "Acerca da questão de se é permitido fugir de uma peste mortal".

48 LUTHER, Martin. Ob man vor dem Sterben fliehen möge (Editorische Bemerkung). In: ALAND, Kurt (Hrsg.). Gesammelte Werke. Bd. 6, p. 336-337.

49 LUTHER, Martin. Ob man vor dem Sterben fliehen möge. In: ALAND, Kurt (Hrsg.). Gesammelte Werke. Bd. 6, p. 228; BRECHT, 1986, p. 206; LINDBERG, 2001, p. 42. 
permanência de "pessoas fracas" em meio às pessoas infectadas. ${ }^{50}$ Em resumo, avalia duplamente a permanência e a fuga em meio à peste: se alguém recebeu ordem e mandamento de Cristo (segundo Mateus 10.28 e 10.33), não deve fugir, mesmo que venha a morrer pela doença. Em especial, Lutero considera que funcionários públicos e pastores, além de médicos, deviam permanecer em suas comunidades para prestarem seus serviços às pessoas adoentadas (recorre, para isso, a João 10.12; Atos 9.25, 19.30; Romanos 13. 6; 1 Timóteo 5.8). Lutero ainda estende a obrigação de permanência aos empregados, pais e mães e filhos e filhas. Pessoas que, nessas circunstâncias, abandonam uma pessoa enferma e fogem são consideradas assassinas por Lutero. Afora isso, a saber, quando não contraria o mandamento e a ordem de Deus, nem ao amor ao próximo, a fuga não é proibida, conforme Efésios 5.29. Pelo contrário, é até ordenada a fuga para preservação de seu corpo e de sua vida. Por isso Lutero concebe como legítima a tentativa de preservar sua vida, inclusive por meio do uso de medicamentos. ${ }^{51}$

No decorrer do texto, Lutero passa a enfatizar de modo crescente a obrigação de socorro ao próximo. Segundo ele, como os hospitais não são suficientes para abrigar todas as pessoas doentes, "[...] nós precisamos deveras ser um para o outro um mestre de hospital e cuidador em suas necessidades, sob ameaça de perda da bem-aventurança e graça de Deus" ${ }^{52}$. Diante da possibilidade da morte, cada pessoa deveria estar preparada ante o castigo e julgamento da fé por Deus. Mas, mais do que isso, Deus não somente quer castigar os pecados, senão que também provar a fé e o amor ao próximo. O medo deveria ser concebido como obra do diabo e combatido. Contrariamente, o serviço em favor das pessoas doentes deveria ser concebido como culto a Deus e envolto de uma grande promessa: a de que Deus mesmo é enfermeiro e médico, diante do qual todos os médicos e farmacêuticos nada são. Por essa razão não mais é preciso ter medo de contágios. ${ }^{53}$ No serviço e cuidado a uma pessoa enferma se encontra ninguém outro a não ser o próprio Cristo:

Queres servir o próprio Cristo e ser seu cuidador, pois bem, então tens diante de ti o teu próximo doente. Vai a ele e serve-o, assim certamente encontrarás Cristo nele, não na Sua pessoa, mas segundo a Sua Palavra. Mas se não queres e não gostas de servir teu próximo, crê deveras: se Cristo mesmo estivesse ali, tu farias a mesma coisa e o abandonarias [...] Ele se tornaria assim culpado da morte de seu próximo e, diante de Deus, um assassino. Deveras, tais pessoas seriam como aquelas que, quando uma casa na

${ }^{50}$ Lutero utiliza o exemplo de duas pessoas, uma fraca e uma forte, que farão uma caminhada. Se a pessoa forte, isto é, fisicamente mais bem preparada, não adequar seu passo ao da pessoa menos preparada, esta logo morrerá.

${ }^{51}$ LUTHER, Martin. Ob man vor dem Sterben fliehen möge. In: ALAND, Kurt (Hrsg.). Gesammelte Werke. Bd. 6, p. 228-231, 234-235; BRECHT, 1986, p. 206.

52 "[...] müssen wir fürwahr einer des andern Spitalmeister und Pfleger sein, in seinen Nöten bei Verlust der Seligkeit und Gottes Gnaden." LUTHER, Martin. Ob man vor dem Sterben fliehen möge. In: ALAND, Kurt (Hrsg.). Gesammelte Werke. Bd. 6, p. 235-236.

${ }^{53}$ LUTHER, Martin. Ob man vor dem Sterben fliehen möge. In: ALAND, Kurt (Hrsg.). Gesammelte Werke. Bd. 6, p. 236- 238; BRECHT, 1986, p. 206. 
cidade pega fogo, não combatem o fogo, mas deixam o fogo alastrar-se, de forma que toda a cidade pegue fogo e ainda dissessem: Se Deus quer, Ele pode proteger a cidade sem água e sem combate ao incêndio ${ }^{54}$.

Lutero não defende um comportamento descuidado e inconsequente que potencializasse o contágio da peste entre as pessoas. Ele insiste no uso de medicamentos e na adoção de princípios de higiene. Por essa razão também admoesta pessoas doentes e convalescentes a se manterem distantes das pessoas saudáveis. Defende que violações comportamentais deveriam ser punidas. ${ }^{55}$ Ele próprio, ao hospedar pessoas enfermas em sua casa, expressa que elas ficavam em alojamento separado, onde eram assistidas e cuidadas. ${ }^{56}$

Ao final do escrito Se é permitido fugir diante da ameaça de morte, Lutero trata do aconselhamento a pessoas doentes. Insistia que as pessoas buscassem na igreja o ensinamento da palavra de Deus. Defendia que pessoas que não tivessem vivido de forma cristã somente deveriam ser assistidas espiritualmente após mostrar arrependimento. A preparação para a morte deveria incluir confissão, comunhão da Santa Ceia, reconciliação com outras pessoas e escrita do testamento. Como era impossível aos pastores e capelães visitarem todas as pessoas acometidas pela epidemia, havendo solicitação de visita, essa deveria ocorrer em tempo, quando a pessoa ainda estivesse consciente - Lutero era contrário à realização de um simples ritual junto à cama de uma pessoa moribunda, já inconsciente. Por razões de higiene, ele ainda pleiteou a transferência do cemitério para fora dos muros da cidade. Por outro lado, também pleiteou que os muros dos cemitérios fossem ornamentados com símbolos, tornando-se espaços santos de silêncio e meditação. ${ }^{57}$

Lutero encarou a peste de forma relativamente simples. Sua própria casa se tornou um hospital para pessoas acometidas pela epidemia, como já destacado. Entre as pessoas infectadas, encontraram hospedagem na casa da família Lutero a esposa do médico Augusto Schurf, e Margareta von Mochau, cunhada de Andreas Bodenstein von Karlstadt. Lutero também manifestou grande preocupação com sua esposa Catarina, que estava grávida, uma vez que Anna, esposa de Jorge Rörer, irmã de João Bugenhagen, que também estava grávida, prestes a dar à luz, havia sido acometida

${ }^{54}$ LUTHER, Martin. Ob man vor dem Sterben fliehen möge. In: ALAND, Kurt (Hrsg.). Gesammelte Werke. Bd. 6, p. 240-241. "Willst du nun Christus selbst dienen und sein warten, wohlan, so hast du da vor dir deinen kranken Nächsten. Gehe hin zu ihm und diene ihm, so findest du gewiß Christus an ihm, nicht nach der Person, sondern in seinem Wort. Willst du aber und magst deinem Nächsten nicht dienen, so glaube fürwahr: wenn Christus selbst da wäre, du tätest auch genau so und ließest ihn liegen. [...] Er würde also auch seines Nächsten Todes schuldig und vielmal vor Gott ein Mörder. Fürwahr, solche Leute sind gerade, als wenn ein Haus in der Stadt brennte, dem niemand wehrte, sondern (man) ließe dem Feuer Raum, daß die ganze Stadt verbrennte, und wollte sagen: wills Gott tun, so wird er die Stadt wohl ohne Wasser und Löschen behüten." (tradução do autor)

55 LUTHER, Martin. Ob man vor dem Sterben fliehen möge. In: ALAND, Kurt (Hrsg.). Gesammelte Werke. Bd. 6, p. 241-244; BRECHT, 1986, p. 206; LINDBERG, 2001, p. 42.

${ }^{56}$ BRECHT, 1986, p. 207.

57 LUTHER, Martin. Ob man vor dem Sterben fliehen möge. In: ALAND, Kurt (Hrsg.). Gesammelte Werke. Bd. 6, p. 244-246; BRECHT, 1986, p. 206-207. 
pela epidemia. E Lutero ficou profundamente abalado quando, em 02 de novembro, Anna Rörer faleceu, após ter dado à luz uma criança natimorta. ${ }^{58}$

A peste implicava isolamento social e aflorava o sentimento de solidão. Por essa razão João Bugenhagen e sua família transferiram residência para o Convento Negro, onde residia a família Lutero. Dessa forma, ambas as famílias podiam gozar de convivência e consolo mútuo. Lutero se externou de forma corajosa sobre as pessoas acometidas pela epidemia. Segundo ele, externamente as pessoas estavam doentes, mas efetivamente reinavam vida e salvação. Ele tinha convicção de que, ao final, a vitória seria de Cristo. Outros conselhos bíblicos, aparentemente, ele próprio não conseguia encontrar, de modo que uma palavra consoladora de Bugenhagen se tornou especial para ele: "Deus pensa assim: o que Eu ainda devo fazer com esta pessoa? Eu lhe dou tão magníficas dádivas e ele duvida da minha graça" 59 .

Aproximadamente pelo dia 20 de novembro de 1527, o surto da epidemia começou a reduzir. Somente os porcos, que Catarina von Bora criava, ainda morreram, fato que Lutero interpretou a partir de Marcos 5.13, segundo o qual Jesus expulsa demônios e ordena que possuam porcos, que se precipitam no mar e morrem. Somente o próprio Lutero, ele ainda se sentia em provação até meados de dezembro daquele ano. Segundo ele próprio, sua ligação com Cristo se dava por um fraco fio, enquanto Satanás o puxava para o fundo com forte cabo. As tentações que Lutero experienciou nesse período podem ser comparadas às que sofreu quando ainda era monge e "brigava" com Deus. ${ }^{60}$

As tentações de Lutero durante a segunda metade do ano de 1527 precisam ser consideradas nas suas Preleções sobre a Primeira Carta de João e, na sequência, também sobre as Cartas a Tito e a Filemom. ${ }^{61}$ Nessas três preleções, que se constituem em "documentos do tempo da peste" ${ }^{2}$, Lutero retoma forte embate com os entusiastas e sacramentários, comparando-os com a vida monástica. Na concepção do reformador, assim como os monges, agora também os entusiastas não queriam confiar somente no Cristo presente por meio da Palavra externa, que, para Lutero em meio às provações, era o único fundamento. Mesmo quando a peste alcançara seu pico e ameaçava a vida, e em meio às provações, Lutero não interrompeu sua atividade docente, mas buscava se refugiar na fé, conforme encontrava no testemunho de Cristo segundo o Evangelho de João. ${ }^{63}$

${ }^{58}$ LUTHER, Martin. An Amsdorf, 1. November 1527. In: ALAND, Kurt (Hrsg.). Gesammelte Werke. Bd. 10, p. 185-186; BRECHT, 1986, p. 207; LINDBERG, 2001, p. 42.

59 "Gott denkt so: Was sol ich mit diesem Menschen noch tun? Ich gab ihm so viele hervorragende Gabe, und er verzweifelt na meiner Gnade." BUGENHAGEN apud BRECHT, 1986, p. 207.

${ }^{60}$ BRECHT, 1986, p. 207-208.

${ }^{61}$ A maior parte do tempo (19 de agosto até 7 de novembro), Lutero se dedicou à interpretação e preleção da Primeira Carta de João. Às preleções sobre as Cartas a Tito e Filemom Lutero dedicou o período de 11 de novembro a 18 de dezembro.

62 BRECHT, 1986, p. 244.

${ }^{63}$ BRECHT, 1986, p. 208. 


\section{Os anos de 1535 a 1539: novo surto de uma peste persistente}

Em julho de 1535, um novo surto de epidemia da peste rondou Wittenberg. Semelhantemente aos surtos anteriores, Lutero minimizou o perigo e recusou o conselho do príncipe-eleitor para se refugiar em outro lugar. ${ }^{64}$ Para Lutero, o perigo estaria sendo superdimensionado pelos estudantes, que desejavam a interrupção das aulas, pressionados por suas mães. Segundo o reformador, não se deveria levar as pessoas a um estado de histeria coletiva. Em suas prédicas, ele dava algumas orientações sobre como preservar-se. Considerou inútil o imaginário que circulava entre as pessoas sobre uma roupa especial que protegesse do contágio da peste. Por outro lado, defendia que se deveria prover pela alimentação das pessoas doentes. Como também já anteriormente, admoestava que as pessoas doentes deveriam se manter distantes das pessoas saudáveis para não contaminá-las. Maridos não deveriam abandonar suas esposas. A comunidade era convidada à comunhão da Santa Ceia, que também era celebrada nas quartas e sextas-feiras. Com isso se desejava possibilitar a participação das pessoas doentes, uma vez que não se conseguia celebrar a Santa Ceia nas casas de todas elas. Em especial, Lutero recusava a celebração na casa de pessoas doentes quando essas já anteriormente não participavam dos cultos na igreja. ${ }^{65}$

A saúde de Lutero continuava frágil também nesses anos. Possivelmente no dia 01 de junho de 1535, após concluir a interpretação do Salmo 90, ele iniciaria sua grande e última obra teológica: a Preleção sobre Gênesis. Ele concluiria essa obra em 17 de novembro de 1545. Mas, logo no início, ele precisou interrompê-la, pois as atividades da Universidade de Wittenberg haviam sido novamente transferidas para Jena em consequência do novo surto de peste. ${ }^{66}$

O surto da epidemia estendeu-se pelos anos seguintes e tornou-se novamente ameaçador no outono de 1538. Ante o temor que se espalhou mais uma vez entre a população, Lutero precisou pregar contra o medo das pessoas, o qual, segundo ele, parecia ser maior do que fora no antigo catolicismo. Quando, então, surgiram os primeiros casos de pessoas contaminadas, Lutero admoestou as pessoas para que não fugissem em pânico, abandonando doentes. A peste deveria ser aceita como punição de Deus (lei). As autoridades da cidade deveriam prover equipes de médicos e enfermeiros para a devida assistência hospitalar. Ele ainda pleiteou que a madeira para aquecimento e a alimentação deixada para trás pelos que abandonaram a cidade deveriam ser confiscadas e distribuídas entre as pessoas pobres. Também nessa ocasião não cogitou abandonar Wittenberg e refugiar-se em outro lugar, demonstrando não ter medo da morte. Mesmo assim, advertia que as pessoas não se expusessem ao perigo do contágio. Colegas diáconos, que assistiam às confissões de culpa, tentaram isolá-lo, ao que se opôs. Lutero cria que ministros geralmente permaneciam preservados de

${ }^{64}$ Lutero respondeu em carta ao príncipe, datada de 09 de julho de 1535. Veja LUTHER, Martin. An Johann Friedrich den Großmütigen, 9. Juli 1535. In: ALAND, Kurt (Hrsg.). Gesammelte Werke. Bd. 10, p. 246-247.

${ }^{65}$ BRECHT, Martin. Martin Luther; Die Erhaltung der Kirche 1532-1546. Stuttgart: Calwer Verlag, 1987. v. 3, p. $27-28$.

${ }^{66}$ BRECHT, 1987, p. 139. 
contágios. Mais tarde, contudo, Lutero manifestou que somente parte do clero deveria ser engajado na assistência aos enfermos da epidemia. Chegou a cogitar a interrupção da celebração da Santa Ceia pela falta de pessoas na comunhão. ${ }^{67}$

Em 1539, a peste passou a contagiar novamente a população de Wittenberg. Novamente ocorreram fugas de pessoas, que deixavam para trás familiares infectados. Em meio a esse surto da epidemia, Lutero e Catarina abrigaram em sua casa os quatro filhos do casal Sebaldo e Ana Münster, que havia falecido em decorrência da peste. Os quatro filhos do casal falecido ficaram na casa dos Lutero até que a esposa de Filipe Melanchthon, que era irmã de Ana Münster, pôde abrigá-los em sua casa. Por ter abrigado as quatro crianças em sua casa, Lutero foi acusado de propagar a epidemia. Ele, contudo, se mantinha convicto de que a epidemia não se alastraria. Para ele, a peste real consistiria na destruição das relações sociais pelo medo da epidemia. ${ }^{68}$ Por essa razão Lutero concebia que "a igreja é uma hospedaria e hospital para doentes e pessoas que necessitam de cuidados. O céu, porém, é a residência dos salvos e justos" $" 69$.

\section{Considerações finais}

A peste tornou-se companheira da vida do ser humano entre os séculos XIV e XVIII. O medo da morte suscitou na humanidade medieval o medo da condenação eterna. A terrível morte, especialmente pela peste, aguçava ainda mais o imaginário de um Deus terrível. A religião tornou-se uma "matemática da salvação do eu", em detrimento da caridade, do amor ao próximo. Por causa da "matemática da salvação do eu", Lutero tornou-se monge para "merecer a salvação". Contudo, a redescoberta evangélica o leva a interpretar a peste na perspectiva de lei e evangelho. Segundo Lutero, a ameaça da morte pela peste se apresenta como punição de Deus pelo pecado humano. Ela é expressão da lei. Mas é lei que move para o evangelho, para a boa-nova. Em meio à realidade da morte, pela fé, o ser humano é liberto do egoísmo para tornar-se um pequeno Cristo para o seu próximo. Na pessoa doente, Cristo é encontrado. Na pessoa enferma, Cristo é servido. Por essa razão, em seus escritos, em particular em Se é permitido fugir diante da ameaça de morte, Lutero não apresenta uma solução moralista e maniqueísta: permanecer e cuidar de pessoas infectadas ou fugir e preservar a própria vida. Para Lutero, vida e cuidado da vida de pessoas enfermas não podem ser contrapostos. Tanto a preservação da própria vida quanto a preservação e cuidado da vida de pessoas enfermas são imperativas. O que define uma ou outra é o chamado. Pessoas que têm a função do cuidado e da assistência a pessoas doentes devem assumir o compromisso com pessoas enfermas. As demais devem se preservar. Conjugadas “evangelicamente", ambas apontam para uma mesma direção: A VIDA!

67 BRECHT, 1987, p. 252.

${ }^{68}$ LUTHER, Martin. An Wenzeslaus Link. 26. Oktober 1539. In: ALAND, Kurt (Hrsg.). Gesammelte Werke. Bd. 10, p. 278; BRECHT, 1987, p. 252-253; JUNGHANS, 2001, p. 178.

${ }^{69}$ LUTHER, Martin. Vorlesung über den Römerbrief (1515/1516). In: ALAND, Kurt (Hrsg.). Gesammelte Werke. Bd. 1, p. 173. "Die Kirche ist eine Herberge und Krankenhaus für Kranke und Pflegebedürftige. Der Himmel aber ist die Residenz der Geretteten und der Gerechten.” (tradução do autor) 


\section{Referências}

ARRUDA, José Jobson de. História Antiga e Medieval. 3. ed. São Paulo: Ática, 1979. BAYER, Oswald. A teologia de Martim Lutero. São Leopoldo: Sinodal, 2007.

BRAUDEL, Fernand. Sozialgeschichte des 15.-18. Jahrhunderts. München: Kindler, 1985.

BRECHT, Martin. Martin Luther; Sein Weg zur Reformation 1483-1521. Stuttgart: Calwer Verlag, 1983. v. 1.

BRECHT, Martin. Martin Luther; Ordnung und Abgrenzung der Reformation 1521-1532. Stuttgart: Calwer Verlag, 1986. v. 2.

BRECHT, Martin. Martin Luther; Die Erhaltung der Kirche 1532-1546. Stuttgart: Calwer Verlag, 1987. v. 3.

DALFERTH, Heloisa Gralow. Katharina von Bora; uma biografia. São Leopoldo: Sinodal, 2000. DER GROSSE PLOETZ. Die Daten-Enzyklopädie der Weltgeschichte. Daten, Fakten Zusammenhängen. Freiburg im Breisgau: Wissenschaftliche Buchgesellschaft, 1998.

GASSMANN, Günther; HENDRIX, Scott. As confissões luteranas: introdução. São Leopoldo: Sinodal, 2002.

JUNGHANS, Helmar. Temas da Teologia de Lutero. São Leopoldo: Sinodal, 2001.

LIENHARD, Marc. Martim Lutero; tempo, vida e mensagem. São Leopoldo: Sinodal, 1998.

LINDBERG, Carter. As Reformas na Europa. São Leopoldo: Sinodal, 2001.

LUTERO, Martinho. Catecismo Maior do Dr. Martinho Lutero. In: Livro de Concórdia; as confissões da Igreja Evangélica Luterana. São Leopoldo: Sinodal; Porto Alegre: Concórdia, 1997. p. 365-496.

. Do cativeiro babilônico da Igreja; um prelúdio de Martinho Lutero. In. Obras Selecionadas. O programa da Reforma Escritos de 1520. São Leopoldo: Sinodal; Porto Alegre: Concórdia, 1989. v. 2, p. 341-460.

. Preleção sobre Gênesis. In: Obras Selecionadas. Interpretação do Antigo Testamento.

São Leopoldo: Sinodal, Porto Alegre: Concórdia; Canoas: Ulbra, 2014. v. 12, p. 53-530.

. Uma Prédica para que se Mandem os Filhos à Escola. In: Obras Selecionadas. Fundamentos - Oração - Sexualidade - Educação - Economia. São Leopoldo: Sinodal; Porto Alegre: Concórdia, 1995. v. 5, p. 331-363.

LUTHER, Luther: Achter Sonntag nach Trinitatis. Matth. 7,15-23. In: ALAND, Kurt (Hrsg.). Gesammelte Werke. Bd. 8, p. 310-316.

10, p. $185-186$.

An Amsdorf, 1. November 1527. In: ALAND, Kurt (Hrsg.). Gesammelte Werke. Bd. 10, p. 18.

. An Joh. Lang. 26. Oktober 1516. In: ALAND, Kurt (Hrsg.). Gesammelte Werke. Bd.

An Johann Friedrich den Großmütigen, 9. Juli 1535. In: ALAND, Kurt (Hrsg.). Gesammelte Werke. Bd. 10, p. 246-247.

. An Nikolaus Haussmann, 5. August 1528. In: ALAND, Kurt (Hrsg.). Gesammelte Werke. Bd. 10, p. 189.

10, p. 183.

An Spatatin, 19. August 1527. In: ALAND, Kurt (Hrsg.). Gesammelte Werke. Bd.

. An Wenzeslaus Link. 26. Oktober 1539. In: ALAND, Kurt (Hrsg.). Gesammelte Werke. Bd. 10, p. 278.

, Brief an Papst Leo X. (Mai 1518). In: ALAND, Kurt (Hrsg.). Gesammelte Werke. Bd. 2, p. 88-91.

. Der Teufel die Ursache von Not, Traurigkeit und Krankheit. Der Christ in der Welt. In: ALAND, Kurt (Hrsg.). Gesammelte Werke. Bd. 9, p. 285. 
LUTHER, Martin. Sonntag Exaudi. Joh. 15,26-16,4. In: ALAND, Kurt (Hrsg.). Gesammelte Werke. Bd. 8, p. 236-242.

. Ob man vor dem Sterben fliehen möge. Gesammelte Werke. Bd. 6, p. 228-246.

. Ob man vor dem Sterben fliehen möge (Editorische Bemerkung). In: ALAND, Kurt

(Hrsg.). Gesammelte Werke. Bd. 6, p. 336-338.

. Über den Krieg. Obrigkeit und Staat. In: ALAND, Kurt (Hrsg.). Gesammelte Werke. Bd. 9, p. 205.

. Vierter Sonntag nach Epiphanias. Matth. 8,23-27. In: ALAND, Kurt (Hrsg.). Gesammelte Werke. Bd. 8, p. 94-102.

. Vierundzwanzigster Sonntag nach Trinitatis. Matth. 9,18-26. In: ALAND, Kurt (Hrsg.). Gesammelte Werke. Bd. 8, p. 415-420.

. Vorlesung über den Römerbrief (1515/1516). In: ALAND, Kurt (Hrsg.). Gesammelte Werke. Bd. 1, p. 106-262.

Zeichen, wenn Gott gnädig oder ungnädig sei. Der neue Glaube. In: ALAND, Kurt (Hrsg.). Gesammelte Werke. Bd. 9, p. 87.

Zweiter Sonntag nach Trinitatis. Luk. 14,16-24. In: ALAND, Kurt (Hrsg.).

Gesammelte Werke. Bd. 8, p. 274-280.

McEVEDY, Colin. Atlas de história medieval. São Paulo: Companhia das Letras, 2007.

WACHHOLZ, Wilhelm. História e teologia da Reforma. São Leopoldo: Sinodal, 2010. 